\title{
La Circularidad en la Poesía de Pablo Neruda
}

Una de las características más notables en la poesía de Pablo Neruda es la referencia al movimiento; y la circularidad, especialmente, ocupa su preferencia. No se trata de una imagen constante, expresada de una manera determinada e invariable, por lo que resulta de clasificación difícil y compleja. El propósito de este trabajo es el de exponer la evolución de algunas imágenes circulares, sus variantes, repeticiones, originalidad, formas y asiduidad de uso, y preferencias del poeta, al mismo tiempo que su función estética. Se pueden distinguir algunas categorías generales: A) Movimiento CIRCULAR EXPRESADO POR Verbos como givar, rodar, dar vueltas, rodear, envolver, cercar, rondar, redondear, ceñir, revolverse, circundar; B) CIRCULARIDAD EXPRESADA POR FRASES: en torno a, alrededor de, en medio, en el centro; y C) CIRCULARIDAD EXPRESADA POR SUSTANTIVOS como rueda, círculo, anillo, sortija, aro, argalla, medialla, corona, nimbo, corola, cintura, cinturón, ronda, globo, planeta, burbuja, uva, manzana, naranja, cereza. En esta última categoría se pueden incluir los adjetivos correspondientes: circundante, girante, redondo, coronado, etc.

Para la interpretación y las conclusiones, nos hemos basado en la teoria propuesta por algunos lingüistas referente a la posibilidad de co. rrespondencia entre la palabra escrita y la imagen visual y auditiva que provoca. Se resume esta teoría en las palabras de Jakobson que Octavio Paz cita: "en poesía 'The sound must seem an echo of the sense'".1 En su conocida obra The meaning of meaning, Ogden y Richards citan a Yeats al respecto: "'All sound', says Yeats, 'evoke indefinable and yet precise emotions... or, as I prefer to think, call down among us certain disembodied powers whose footsteps over our bearts we call

1 Claude Lévi-Strauss o el nuevo festín de Esopo (México, 1967), p. 61. 
emotion", 2 expresándose en esta instancia una correspondencia entre los sonidos y las emociones. Por otra parte, Scheerer y Lyons condujeron un experimento con niños y niñas de 11 y 7 años respectivamente, por el cual pudieron establecer que la vocal $i$ se asociaba con los atributos visuales de delgadez, pequeñez y angulosidad; y las vocales $o$ y a con atributos visuales de grosor, volumen y redondez. ${ }^{3}$ También Edward Sapir y Charles Osgood, entre los más notables, han dedicado varias páginas a este tema en libros como Language y The Measurement of Meaning. Otro especialista, Hymes, afirma "Even the existence of universal sound symbolism cannot be dogmatically denied". ${ }^{4} \mathrm{La}$ teoría ha sido estudiada a fondo por los lingüistas, y la polémica todavía continúa.

Debido a la abundancia de la obra de Neruda, no es posible guiarse solamente por la cantidad de repetición para determinar la intención del poeta. Sin embargo, en el caso de la circularidad, la cantidad resulta elocuente, especialmente si se toma en cuenta la recurrencia de los ejemplos y sus variantes. Nos interesa ver cómo Neruda hace uso de esta imagen a través de su poesía y qué intenta transmitir a través de ella. Algunos de los verbos y expresiones referentes a la circularidad pierden algo de su fuerza sugestiva a lo largo de la obra del poeta, como en el caso de rodear, rodeado, en medio de, en el centro. En general, esto sucede por repetición que conduce al desgaste, y por carecer estas expresiones de las posibilidades que tienen otras que analizaremos más adelante, a pesar de lo cual el énfasis en la circularidad es tan grande, que hasta el crítico se siente envuelto en ella, quizá inconscientemente -Amado Alonso dice del poeta: "Pablo Neruda está ensimismado en la angustiosa incertidumbre del hombre ante su mera existencia, y se siente solo, solitario en el mundo y rodeado de una corteza de exterioridad. . Una corteza extraña es el mundo, y de ella es centra la pepita de su yo, siempre centro por más que se traslade". 5 Esta es una de las escasas menciones que se han hecho de la imagen circular en la obra del poeta.

En las Residencias es donde encontramos el mayor número de apariciones del verbo rodear y sus derivados. Por medio de este verbo se expresa la característica más sobresaliente del período de mayor soledad y aislamiento del poeta. Los ejemplos siguientes ilustran el uso de este

2 (New York, 1938), p. 45.

3 Martin Scheerer and Joseph Lyons, "Line drawings and matching responses to words." Journal of Personality, Vol. 25, No. 3 (March, 1957), p. 271.

4 Dell H. Hymes, "Phonological Aspects of Style: Some English Sonnets," en Style in language, edited by Thomas A. Sebeok, Cambridge, Mass., 1960, p. 112.

5 Amado Alonso, Poesia y estilo de Pablo Neruda (Buenos Aires, 1940), p. 235. Los subrayados son nuestros. 
verbo a través de la poesía de Neruda. Aparece por primera vez en Crepusculario: ${ }^{6}$

El horizonte, como un brazo rodea la fruta encendida del sol cayendo en el ocaso. (83)

En Tentativa de bombre infinito, el poeta se dirige a la noche:

cuando rodeas los animales del sueño. (57)

En Residencio en la tierra encontramos una gran proliferación del verbo rodear, empleado generalmente en situaciones similares: el poeta está en el centro y todo lo exterior se une, rodeándolo, y logra sumirlo en una soledad y un sufrimiento aún más profundos. Neruda crea con eficacia esa sensación de aislamiento, donde su actitud personal se refleja en la poesía, caracterizando una etapa inconfundible (si bien ésta se habrá de superar), de su labor poética. La técnica que emplea en esta etapa es casi invatiable: se trata genetalmente de algo externo que rodea al poeta, separándolo del mundo; es algo (como la noche o el mar), que a veces rodea a otra entidad más débil y con menores posibilidades - a voluntad- de defenderse. También la obra poética en sí comparte esta situación, aislada pero en mayor comunión con la naturaleza, coincidiendo con un período menos ensimismado del poeta:

6 Damos a continuación una lista de las ediciones usadas en este trabajo. La paginación indicada entre paréntesis se refiere a estas ediciones:

Crepusculario (Buenos. Aires, 1967).

Veinte poemas de amor y una canción desesperada (Buenos Aires, 1966).

El babitante y su esperanza. El bondero entusiasta. Tentativa del bombre infinito. Anillos (Buenos Aires, 1964).

Residencia en la tierra (Buenos Aires, 1966).

Tercera residencia (Buenos Aires, 1961).

Canto general (México, 1952).

Las uvas y el viento en Obras Completas (Buenos Aires, 1964).

Los versos del Capitán (Buenos Aires, 1966).

Odas elementales (Buenos Aires, 1967).

Nuevas odas elementales (Buenos Aires, 1963).

Tercer libro de Odas en Obras Completas, 2a. edición (Buenos Aires, 1957).

Estravagario (Buenos Aires, 1958).

Canción de gesta (Montevideo, 1962).

Navegaciones y regresos (Buenos Aires, 1959).

Las piedras de Chile (Buenos Aires, 1960).

Cantos ceremoniales (Buenos Aires, 1961).

Plenos poderes (Buenos Aires, 1962).

Memorial de Isla Negra (Buenos Aires, 1964), 5 volúmenes. 
$\mathbf{Y}$ así fue cómo

fue este libro naciendo

rodeado de mar y limoneros.

(Las uvas y el viento, 768)

En las Odas elementales, el yo del poeta se pluraliza:

nos rodearon los números (142),

y se usa el tiempo pretérito del verbo, indicando un peligro que existió pero que ya no está presente.

En Nuevas odas elementales, todavía se aúnan los elementos rodeanod al poeta, pero notamos un cambio: ya no son amenazadores, no lo acosan; ahora el poeta, en su posición central, siente mayor comunión con las fuerzas de la naturaleza a su alrededor (caso similar al mencionado de Las uvas $y$ el viento):

Océano,

tu desbordante copa

abre

como en la roca

su agujero

en mi pequeña frente de poeta,

y arena, flores duras, aves

de tempestad, silbante cielo,

rodean mi existencia. (63)

Esta actitud resalta aún más en Navegaciones y regresos, donde de nuevo se dirige al océano:

Océano perdido

por mi razón errante,

vuelvo a encontrar sin tregua

rodeándome,

abrazando en tu círculo mi vida. (51)

Otra vez observamos que ha dasaparecido toda amenaza, que Neruda ahora puede sentirse seguro en medio del agua que lo rodea. Técnica. mente, la posición del verbo en un verso de la estrofa lo hace resaltar aún más, debido al efecto visual que produce, y también por el uso del 
gerundio, que acentúa la continuidad del movimiento. Agregado a todo esto, el uso del complemento como sufijo alarga el verbo, dándole mayor sonoridad. Ya en Plenos poderes, el movimiento que transmite el verbo se ha convertido en pretérito:
En esta grave torre
no hay combate:
la niebla, el aire, el día
la rodearon, se fueron
y me quedé con cielo y con papel, solitarias dulzuras y deberes. (20)

La amenaza que acechaba ya no existe. En el ejemplo citado hay mayor reiteración de la inexistencia del peligro por medio del verbo que indica la desaparición: "se fueron." Finalmente, en el último poema del volumen, el verbo rodeat aparece con dualidad desconocida:

Así lo que en la muerte me rodea abre en mí la ventana de la vida $y$ en pleno paroxismo estoy durmiendo. (86)

El verbo se asocia con un elemento negativo, la muerte, pero ésta existe como una introducción a un período más vital; se da la posibilidad de una etapa de reposo que precede a un despertar. El círculo cerrado se rompe y en él se abre una ventana que indica la salida, la salvación.

El verbo girar, como se verá más adelante, es mucho más dinámico que el anterior. Neruda no abusa de este verbo, como lo hace con rodear. En Veinte poemas de amor hay varios ejemplos:

Hojas secas de otoño giraban en tu alma (34)

Girante, errante noche, la cavadora de ojos. (55)

En este último ejemplo, su uso resulta muy efectivo, pues al adjetivarse y por su posición al lado de otro término fónico similar, da la idea de búsqueda más intensa; el verbo se alarga sonoramente. Del mismo volumen es el verso:

La luna hace girar su rodaje de sueño (88)

donde, al combinar el verbo con la palabra rodaje, otro término que indica movimiento circular, y con luna, que en general aparece en su 
poesía como una esfera, Neruda logta crear una imagen circular diná. mica y eficaz. El sonido $g$ repetido da mayor expresión al movimiento giratorio. En el verso:

El viento de la noche gira en el cielo y canta (95)

se acentúa el sonido, que irrumpe en la placidez de la sibilante que sigue, en la longitud somnolienta de las nasales y en la calidez de las vocales cercanas. En El bondero entusiasta, el verbo contribuye a la rapidez del movimiento que se quiere transmitir:

Hago girar mis brazos como dos aspas locas (31)

movimiento continuo y desconcertado que desentona con el ambiente creado en la estrofa:

en la noche toda ella de metales azules (31)

aunque "metales azules" connota algo frío y duro. El hondero se en. tusiasma, y en ese mismo poema (que lleva por título la primera línea: "Hago girar mis brazos como dos aspas locas"), desborda en giros:

Pero mis hondas giran.

Gira mi brazo entonces y centellea mi alma.

He aquí los cauces locos que hacen girar mis hondas!

para terminar con los siguientes versos:

En la noche toda ella de astros fríos y errantes hago girar mis brazos como dos aspas locas (32.33)

volviendo así a la misma imagen de las primeras líneas. Con esto se da al poema un enorme marco que contiene los giros internos. La circularidad que se quiere transmitir en esta instancia por medio del verbo girar da una idea de desconcierto, vana defensa, pérdida de control, o falta de voluntad de control. Por medio de la repetición, Neruda consigue crear un efecto de movimiento circular continuo, que acentúa la misma idea ya contenida en el verbo girar. En ocasiones, Neruda usa el verbo girar unido a otro de significado similar, para dar mayor énfasis al movimiento: 
los planetas dan vueltas como husos entusiastas giran (Tentativa, 60)

En su alabanza de la noche, el poeta selecciona el movimiento que la caracteriza mejor. El verso citado presenta gran contraste con el que le sigue:

el corazón del mundo se repliega y se estira (60)

donde el movimiento no es ya circular sino de pulsación, fuertemente vital.

En las Residencias, el uso del verbo girar es escaso; lo mismo ocurre en Los versos del Capitán y en el Canto general. En este último volumen, sin embargo, encontramos algún ejemplo de correspondencia estética entre el verbo y el resto de la estrofa:

El Magdalena lleva al mar su cuerpo

y del mar a otros ríos, a otras aguas

y a otros mares y a otros pequeños ríos

girando alrededor de la tierra. (340)

La imagen de movimiento giratorio está perfectamente integrada; su posición en el verso final condensa lo expresado, y ayuda con su sonido inicial sonoro y seco a romper el ritmo de cadenza y traernos a una realidad auditiva $y$ visual. Lo que fuera encadenamiento lineal se cierra indefinidamente.

La única incidencia de este verbo en Las uvas y el viento es la si. guiente:

$Y$ desde el mar girando en tu contorno

hice un anillo de agua (766)

Es una reiteración de una imagen usada por el poeta con anterioridad pero que, por su posición en relación al sustantivo anillo, consigue sugerir una imagen poderosa de circularidad. En las Odas, dice Neruda, refiriéndose al albatros:

Hermoso eras girando

apenas

entre la ola y el aire

(Tercer libro de la odas, 1295) 
La presencia del aire y su vuelo adquieren mayor permanencia debido al uso del gerundio, al indicar una acción que continúa indefinidamente. En Oda a un cine de pueblo, la imagen se expresa así:

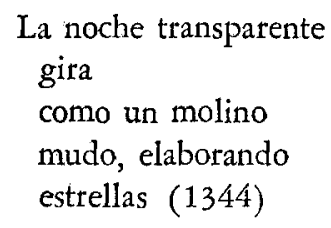

En la poesía de Neruda, esta combinación del verbo con la noche y el molino es común. Se ve, sin embargo, la importancia que el poeta da al verbo apartándolo en un verso, es decir, haciendo uso de una imagen visual y también aislándolo sonoramente en la estrofa. Debemos esperar hasta 1964 para encontrar otra recurrencia de este verbo. En Memorial de Isla Negra, dice:

Sube y vuelve la voz del débil solitario, gira y gira la rueda atroz de las desdichas

$(\mathrm{I}, 84)$

Por el uso de la reiteración Neruda transmite la continuidad del movimiento, que así da la impresión de algo que no acaba, de un círculo vicioso. El tono de la melancolía que prevalece en todo este primer volumen está bien ilustrado en este ejemplo.

El verbo dar vueltas también expresa movimiento circular. En Veinte poemas de amor encontramos:

Fragua de metales azules, noches de calladas

luchas,

mi corazón da vueltas como un volante loco (55)

Estos versos nos recuerdan aquellos otros tan entusiastas de El bondero, donde un pensamiento similar está expresado con el verbo girar. En el poema "Pacaypallá" de Estravagario, aparece en los primeros versos:

Ya está la tierra en torno

a mí dándome vueltas

como el metal al son de la campana (253)

7 El bondero entusiasta, pp. 31-33. 
Con el uso del gerundio en la frase verbal "dándome vueltas", se con. sigue armonizar el verbo con los sonidos de emes y enes que aparecen en muchas palabras de la estrofa. Luego el poema se desarrolla en imá. genes circulares, pero no se usa ningún otro verbo o expresión que denote circularidad. Sin embargo, el resultado y el efecto total es de un vasto movimiento cíclico, que se acentúa por medio del abundante uso de las vocales $o$ y a y por la idea del regreso:

Errante amor, retorno con este corazón fresco y cansado que pertenece al agua y a la arena ........................

a la batalla blanca de la espuma (254)

Es con otro vocablo que creemos que Netuda desarrolla su máximo poder de evocaciones fónicas y visuales, aunque llega al borde de la des. integración por repetirse demasiado. Se trata del verbo rodar, ligado a menudo al sustantivo ruedd. La consonante inicial especialmente; es un eficaz elemento auditivo que consigue recrear el movimiento al ser enun. ciada. Pero lo que se destaca más es la combinación de dos elementos esenciales: forma y movimiento. A medida que decrece el uso de dar vueltas, aumentan las ruedas. Neruda comienza a usar el verbo rodor cada vez más a menudo, y en ocasiones parece preferitlo a otros como caer para expresar caídas hacia el fondo, al abismo de la muerte-caídas sin posibilidad de levantarse, caídas no lineales ni directas sino en forma circulares. Resulta más eficaz que caer, pues es una manera más lenta de caída, como si fuera contra la voluntad del que ejecuta la acción, como si la persona o cosa tratara de defenderse, retardando el momento de la inmovilidad final, al it retrocediendo, aunque sea un poco, en su caída. La transcripción gráfica de este tipo de caída puede ayudar a darnos una idea de este movimiento: De Plenos poderes es el siguiente ejemplo, que muestra las posibilidades del vocablo:

se fue a morir rodando

como piedra del río (82)

Otro ejemplo del uso de este verbo, usado con connotaciones negativas igual que en el anterior, lo encontramos en Residencia en la tierra:

La espesa rueda de la tierra

su llanta húmeda de olvido 
hace rodar, cortando el tiempo

en mitades innacesibles (25-26)

Aquí el verbo se asocia al olvido, en el caso anterior a la muerte. El movimiento, en este último ejemplo, es más cerrado que en el anterior por el uso de las palabras rueda y llanta asociadas al verbo. De todos modos, en los dos ejemplos se usa igualmente el verbo rodar para indicar la caída fatal y decisiva pero no directa.

En Navegaciones y regresos, Neruda usa el verbo nuevamente con sen. tido negativo; hablando de floreros, dice:

$$
\begin{aligned}
& \text { y otro vacio } \\
& \text { rodó, rodó, rodó } \\
& \text { por el invierno } \\
& \text { hasta ser sólo harina } \\
& \text { del florero, } \\
& \text { recuerdo roto, polvo luminoso. }
\end{aligned}
$$

Estas líneas corresponden a la "Oda a las cosas rotas", donde se destaca Ia función negativa que el poeta asigna a menudo al verbo rodar. El movimiento circular es muy marcado y se obtiene por el sonido repetido de la consonante inicial $r$, por el aislamiento del verso donde se repite el verbo tres veces, y por el uso del pretérito que, con su empleo exclusivo de la $o$, consigue dar al movimiento una fuerte sensación visual. En el "Epílogo" del mismo volumen, este movimiento se destaca y se vuelve más personal que en casos anteriores:

$$
\begin{aligned}
& \text { A toda rueda digo, } \\
& \text { espera, rueda, espera: } \\
& \text { ya voy, ya vengo, un solo } \\
& \text { minuto } \\
& \text { y rodaremos. } \\
& \text { Sí, rueda, rodaremos, } \\
& \text { insecto, insectaremos, } \\
& \text { sí, fuego, fuegaremos.(142) }
\end{aligned}
$$

Los dos últimos versos, especialmente, ayudan a comprender mejor la función de la rueda, y muestran a Neruda en uno de sus mejores mo. mentos de creación. No sólo aparece en este ejemplo el verbo rodar, sino que también está presente la rueda a la que Neruda invoca y con la que 
quiere it. Así él mismo se integra con uno de los movimientos que es tan esencial para él: el circular. En esa circularidad Neruda resume una función básica de la vida, que es la misma que expresan los verbos insectar y fuegar, y que esencialmente significa vivir, pero en una vivencia de participación intensa, en oposición a la actitud ensimismada de la primera época de su poesía. Esto junto con un optimismo más marcado, en dirección a la vida compartida. También hay mayor juego de contrastes y combionaciones. De Estravagario es el siguiente ejemplo:

$$
\begin{aligned}
& \text { [un día] corrió como una rueda... } \\
& \text { se enrolló... } \\
& \text { Las semanas se enrollan... } \\
& \text { hasta que un día el viento. . } \\
& \text { las abre, las extiende. . (199-200) }
\end{aligned}
$$

Aquí, en combinación con otro verbo de movimiento circular, enrollarse, y en contraposición a otros, abrir, exiender, correr, Neruda crea un cuadro dinámico, casi violento, de movimiento circular que se destruye súbitamente. Otro contraste de movimiento, en el que la aliteración resulta muy efectiva, aparece en "Ay qué sábados más profundos" del mismo volumen:

$$
\begin{aligned}
& \text { y cuantas muchachas inmóviles } \\
& \text { raptadas por rápidas ruedas (221) }
\end{aligned}
$$

La aliteración, así como los demás sonidos empleados, combinados con el nivel semántico, sirven para crear una imagen de movimiento en cres. cendo, como si se tratara de un tren que va acelerando su marcha; lo oímos y lo visualizamos. Las ruedas adquieren fuerza cada vez más vital, que se acentúa en volúmenes posteriores, como en Canción de gesta:

Si me saludas en remotos puertos

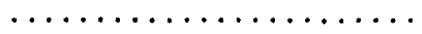

es porque allí pasó mi poesía con su rueda de amor y de venganza (35)

La rueda, en movimiento continuo, siempre en avance, tiene cada vez carga más potente. En Cantos ceremoniales se continúa la misma idea:

desvencijado como un carro viejo que dejó una por una sus ruedas en la luna (10) 
Sin ruedas, el carro es viejo, desvencijado, no sirve, no puede cumplir su función; las fue perdiendo de a poco, como si constituyeran el impulso vital que se va desgastando. La idea está expresada en un verso en el que se hace uso de la rima interior que acentúa la pérdida por medio del sonido y de la repetición.

Finalmente, el rodar se integra indisolublemente a la vida, como lo vemos en el poema titulado precisamente "La creación" de Las piedras de Chile:

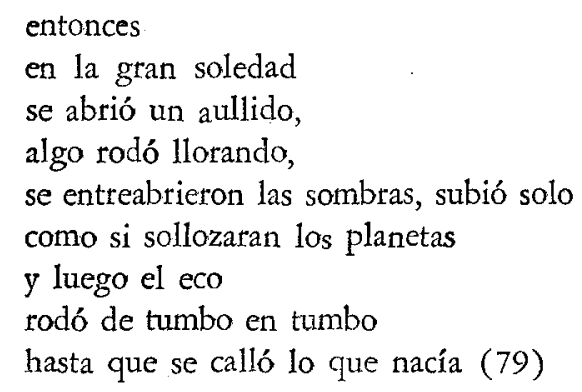

El modo de expresión es vigoroso; el crescendo no sólo se expresa en el aumento de la longitud de los versos sino también por medio de los verbos como abrir, subir, y de la idea de continuación expresada en el verbo rodar. El verbo va cobrando cada vez mayor impulso y luego de a poco, llega a un gradual descenso de tensión para desembocar finalmente en el silencio. En el soneto LXXXI de Cien sonetos de amor hay una parcial resurrección de antiguas imágenes de la juventud del poeta:

Gira la noche sobre sus invisibles ruedas

y junto a mí eres pura como el ámbar dormido (99)

Nuevamente se juega con contrastes de movimiento y quietud. Neruda no abandona totalmente la imagen expresada con el vocablo rueda, pero vemos que su uso es cada vez más escaso. De los cinco volúmenes del Memorial de Isla Negra, aparece en el primero, Donde nace la lluvia, en el poema "Los abandonados":

la soledad es el polvo inútil del mundo, la rueda que da vueltas sin tierra, ni agua, ni hombre (83)

Neruda recapitula sobre su primera época de soledad y aislamiento, re. calcando la idea de lo negativo de esa actitud, como se establece en los 
versos citados. El ritmo lento contribuye a dar énfasis a lo que el poeta expresa. Vuelve a aparecer la meda en el quinto volumen, en el poema "Se amanece":

Se amanece sin deudas

y sin dudas

y luego

cambia el día

rueda la rueda,

se transfigura el juego. (25)

A través del verbo, junto con su correspondiente sustantivo que repite la palabra, se introduce un cambio hacia lo negativo.

Otras expresiones que implican circularidad también tienen un lugat prominente en la poesía de Neruda. Hay varios términos que el poeta usa para enfatizar posición y contraste: en medio de, en el centro, central, vs. en torno a, alrededor de, circundante. En el primer grupo, la posición es central, interna; en el segundo es exterior. Aparecen esos términos principalmente en las primeras obras de Neruda, pero es difícil encon. trarlos más allá del Canto general. Sirven, como hemos visto en otros casos, para dar énfasis al aislamiento de Neruda en la primera etapa de su poesía. En Tercera residencia nos encontramos ante una avalancha:

desde los enlutados alambres, al Sur, en medio, en torno, sin cielo, sin misterio, hombres como un collar de cordones defienden la ciudad rodeada por las llamas: Madrid endurecida (73)

En nuestros subrayados, vemos la intención de Neruda: transmitir el estado de sitio por medio de varias imágenes que, al repetirse tanto, dan gran énfasis a la idea.

Neruda usa también muchos sustantivos que dan idea de circularidad y que a menudo hacen que sus versos adquieran formas y se conviertan en esculturas esbeltas o vacíos abismales. Entre sus preferidos aparecen circulo, estilo, collar, cintura y cinturón. En la mayoría de los casos, el efecto artístico es visual. El movimiento lo dan mayormente los verbos:

La energía se orilla

la cinta

de las fecundaciones 
enrolla

sus anillos (Odas elementales, 144)

En los versos siguientes:

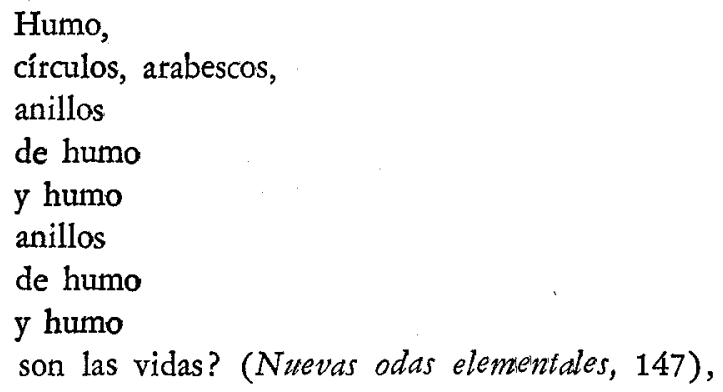

al referirse a anillos de humo, y por medio de la repetición constante, Neruda recurre a la imagen visual de las volutas que se van esfumando, dándoles a los anillos cierto movimiento, aunque muy lento. En los siguientes versos de "Exilio" de Memorial de Isla Negra, tercer volumen:

El destierro es redondo:

un círculo, un anillo:

le dan vuelta tus pies (121)

vemos cómo Neruda combina varias expresiones que indican circularidad y crea su mundo poético donde hasta el destierro se convierte en algo redondo. Con esta asociación Neruda vuelve a insistir en lo expresado en la primera etapa de su poesía: el aislamiento en que una persona puede caer cuando se convierte en su propio centro, y ahora destaca lo peligroso y negativo de esta actitud. Pero esa etapa se pudo superar $y$ en las Odas elementales, Neruda ya expresó:

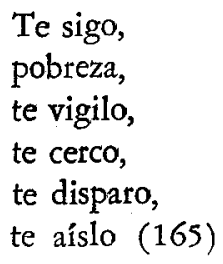

Se han trocado los papeles: el poeta es el que acosa y se convierte en factor circundante, no circundado. De agente receptor pasa a ser ejecutor. El movimiento circular lo establece él con referencia a algo exterior. 
Aún en situaciones evidentemente estáticas, se manifiesta la preferencia de Neruda por imágenes de movimiento. Podemos hablar de su hábil manejo del "movimiento estático":

Arriba iban los cerros amarillos, secos como camellos, en un viaje en que nada se movía, en un viaje de muertos (Cantos ceremoniales, 20)

Lo apasionan, también, los movimientos circulares en gran escala, que se convertirán en un gran movimiento cíclico en el que desemboca su poesía:

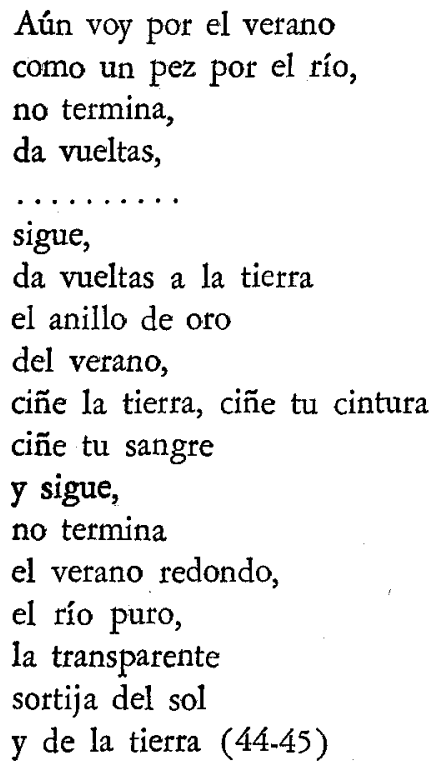

El resultado es un canto vigoroso a la circularidad, tanto en movimiento como en forma y que, como el último verso lo denota, es un canto al planeta que habita el hombre, un canto a la vida.

La circularidad es una de las imágenes preferidas de Neruda que le permite expresar mejor sus estados anímicos. El círculo cerrado de su primera etapa se convierte en una rueda vital que, después de girar locamente, toma una dirección determinada. A medida que crece el optimismo del poeta, las cosas dejan de rodar hacia el abismo, hacia la muerte, y el movimiento no termina abruptamente; se torna cíclico: 
y luego el tiempo vino y vino, se fue y se fue, volvió y volvió (Piedras de Chile, 12)

y así siguió la espiga desgranándose

y el ciclo de las vidas continúa (Cantos ceremoniales, 108)

La naturaleza renace con el cambio de las estaciones; el poeta experimenta un eterno retorno a la vez que un renacimiento:

Cambia el color del mes, crece la barba

del otoño marino,

y yo me llamo Pablo

voy y vengo del mar y sus países

de tierra en tierra fui avanzando

y siempre regresé (Cantos ceremoniales, 110)

el resplandor de un día...

vuelve mañana, vuelve si volvemos (109)

Como hemos visto, la circularidad es un motivo estético de importancia básica en la poesía de Pablo Neruda. Sabe usarlo para producir toda clase de efectos visuales y auditivos, aprovechando también el nivel semántico de los vocablos. Al leer la poesía de Neruda asistimos al nacimiento de la idea de circularidad y a sus primeras manifestaciones, la seguimos en su evolución y subsiguiente desgaste y por fin la vemo renacer con nueva fuerza artística en un gran movimiento cíclico. Este movimiento alcanza a toda su obra, a toda su vida, como lo atestiguain las palabras del poeta: "No renuncio a seguir atesorando todas las cosas que yo haya visto o amado, todo lo que haya sentido, vivido, luchado, para seguir escribiendo el largo poema cíclico que aún no he terminado, porque lo terminará mi última palabra en el final instante de mi vida" ".8

University of Illinois

Martha Paley de Francescato

8 Emir Rodríguez Monegal, El viajero inmóvil. Introducción a Pablo Neruda (Buenos Aires, 1966), p. 326. 